\title{
DESAIN MEJA KERJA STAF ADMINISTRASI SMAN 7 SAMARINDA
}

\author{
M.Wakhid Briyan Adam \\ Mahasiswa Program Studi Desain Produk, Jurusan Desain \\ Politeknik Negeri Samarinda \\ Darius Shyafary \\ Staf Pengajar Program Studi Desain Produk, Jurusan Desain \\ Politeknik Negeri Samarinda \\ Email: dariusshyafari@gmail.com
}

\begin{abstract}
Abstrak
Meja adalah salah satu furniture yang memiliki permukaan datar dan bagian bawahnya disokong oleh empat kaki dan memiliki sebuah laci. Yang dimaksud dengan meja kerja adalah suatu produk yang digunakan oleh direktur, staf maupun pegawai sebagai alas untuk menyelesaikan pekerjaan kantor. Dalam pekerjaan seorang Staf Administrasi SMAN 7 Samarinda pastinya menggunakan sebuah meja yang dapat memenuhi semua kebutuhan dalam bekerja, Salah satunya adalah tempat penyimpanan berkas pekerjaan dan memiliki ukuran yang sesuai dengan ruangan yang ada. Saat ini Staf Administrasi SMAN 7 Samarinda memiliki meja kerja yang ada pada umumnya, akan tetapi memiliki kondisi yang kurang memadahi seperti halnya pada laci penyimpanan berkas yang rusak atau bolong serta belum adanya modifikasi sesuai dengan kebutuhan penggunanya dalam hal kenyamanan dan fungsionalnya. Dengan kondisi tersebut si pengguna itu sendiri harus meletakkan berkas-berkas pekerjaan diatas meja. Dengan metode yang sudah dilakukan di antaranya, prelimanary design, design development dan final design, maka didapatkan hasil akhir perancangan meja kerja staf Administrasi SMAN 7 Samarinda yang sesuai dengan kebutuhan konsumen dan kenyamanan pada saat digunakan serta diperlukan modifikasi. Dengan dibuatnya Meja Kerja ini dapat membantu aktivitas pekerjaan Staf Administrasi SMAN 7 Samarinda.
\end{abstract}

Kata Kunci : meja,meja kerja, minimalis.

\begin{abstract}
A table is one of the furniture that has a flat surface and the bottom is supported by four legs and has a drawer. What is meant by a work desk is a product that is used by directors, staff and employees as a base for completing office work. In the work of an Administrative Staff of SMAN 7 Samarinda, of course, using a table that can fulfill all the needs of work, one of which is a file storage job and has a size that matches the existing room. Currently the SMAN 7 Samarinda Administrative Staff has an existing work desk in general, but has less adequate conditions such as in damaged or perforated file storage drawers and there has been no modification in accordance with the user's needs in terms of comfort and functionality. Under these conditions the user himself must put the work files on the table. With the methods that have been carried out including, data collection, data analysis, and final design, the final results of the design of the SMAN 7 Samarinda Administration staff work table are in accordance with consumer needs and convenience when used and modifications needed. With the creation of this Work Desk can help work activities Administrative Staff of SMAN 7 Samarinda.
\end{abstract}

Keywords: desk, work desk, minimalist. 
I. Pendahuluan

Meja adalah salah satu furniture yang memiliki permukaan datar dan bagian bawahnya disokong oleh empat kaki dan memiliki sebuah laci. Salah satu jenis meja yaitu meja kerja. Yang dimaksud dengan meja kerja adalah suatu produk yang digunakan oleh direktur, staf maupun pegawai sebagai alas untuk menyelesaikan pekerjaan kantor. Selain digunakan sebagai alas, fungsi lainnya yaitu sebagai tempat untuk meletakkan alat-alat kantor seperti komputer, berkas-berkas penting, pena. Ada berbagai pilihan meja kerja kantor, masing-masing bisa dipilih sesuai dengan fungsi dan ukurannya (provokantor.com, 2019).

Menurut Sianipar (2007) pada dasarnya meja kerja biasanya terdapat laci sebagai wadah penyimpanan berkas-berkas penting dan peralatan bekerja lainnya. Untuk dapat menemukan berkas-berkas yang ingin diperlukan kembali, berkas biasanya dikelompokkan dalam suatu map atau folder yang berbeda lalu menyimpannya kembali pada loker atau laci yang sudah terdapat pada meja kerja tersebut. Sama halnya seperti berkas-berkas penting, peralatan kerja lainnya pun dapat disimpan pada salah satunya loker atau laci pada meja kerja yang diperlukan di sekolah.

SMAN 7 Samarinda merupakan salah satu sekolah menengah atas negeri yang ada di Provinsi Kalimantan Timur, Indonesia. Sama dengan SMA Negeri pada umumnya di Indonesia, masa pendidikan SMAN 7 Samarinda ditempuh dalam waktu 3 tahun pelajaran, mulai dari kelas $\mathrm{X}$ sampai dengan kelas XII.

Pada sekolah ini sendiri disediakan meja kerja yang digunakan untuk para staf bekerja. Namun untuk meja kerja yang ada pada bagian staf administrasi SMAN $7 \mathrm{Sa}$ marinda ini memiliki kondisi yang kurang memadahi seperti halnya pada bagian laci atau loker terdapat beberapa yang rusak atau pun bolong serta belum adanya modifikasi sesuai dengan kebutuhan penggunanya dalam hal kenyamanan dan fungsionalnya.
Dengan kondisi tersebut si pengguna itu sendiri harus meletakkan berkas-berkas pekerjaan diatas meja dan tidak adanya ruang khusus untuk meletakkan CPU yang mana CPU itu sendiri diletakkan pada bagian atas meja. Dari permasalahan yang sudah dibahas maka diperlukan rancangan Meja Staf Administrasi SMAN 7 Samarinda sesuai kebutuhan konsumen dan diperlukan modifikasi.

\section{Metode Perancangan}

Untuk metode perancangan ini menggunakan (Goel, 1995). Metode ini dipakai karena sangat cocok untuk diaplikasikan pada meja kerja yang ingin dibuat. Dalam metode perancangan ini dapat di lihat beberapa tahapan desain pelaksanaan yang harus di lakukan secara terus menerus adalah:

\section{Preliminery Design}

Pengumpulan data-data informasi, analisis data berdasarkan konsep desain makro yang diliputi analisis konsep (konsep fungsi, konsep pemakaian, konsep pasar, dan konsep produk), penyusunan program desain dan sketsa awal. Dari bagian di atas terdiri dari: Perumusan Masalah, Tinjauan Pustaka, Analisis Data

\section{Design Development}

Pada tahap ini dibuat alternatif gambar komponen serta rancangan secara wire diagram dengan bentuk sketsa dan 3D (tiga dimensi) dari bagian yang tertera di atas terdiri dari berbagai Alternatif Desain

\section{Final Desain dan Prototipe}

Di buat gambar-gambar yaitu dengan presentasi 3D dan gambar teknik (gambar- gambar tampak, potongan, gambar detail, dan spesifikasi teknik produk). Tahapan selanjutnya adalah pembuatan komponen-komponen dilakukan assembling (exploded) atau perakitan sehingga menjadi produk (prototype). Pada bagian ini terdiri dari: Poster, Portfolio, Gambar Teknik, 
Vol. 6, No. 2, April 2019

Gambar Presentasi, gambar produk dan gambar 3dmax.

\section{Pembahasan}

\subsection{Studi Aktivitas dan Kebutuhan}

Analisis aktivitas dan kebutuhan dilakukan untuk mengetahui aktivitas yang di lakukan dan kebutuhan yang harus di penuhi pada ukuran ruangan $200 \times 100$ $\mathrm{cm}$. Dari hasil analisis aktivitas dan kebutuhan, didapat kesimpulan mengenai komponen-komponen apa saja yang harus ada pada produk. Adapun komponen-komponen tersebut adalah sebagai berikut :

- Pengguna ingin menyimpan alat tulis maka dibutuhkan laci penyimpanan yang berukuran $60 \times 38 \times 20 \mathrm{~cm}$.

- Pengguna ingin menyimpan berkas berkas pekerjaan maka di butuhkan laci atau loker berukuran $60 \times 38 \times 15 \mathrm{~cm}$.

- Di butuhkan laci khusus keyboard yang menggunakan sistem rel mekanik berukuran $45 \times 50 \times 10 \mathrm{~cm}$.

- Laci khusus untuk meletakkan CPU berukuran 60 × $35 \times 48 \mathrm{~cm}$.

- Memiliki ukuran meja yang sesuai apabila meja di isi dengan Komputer, Printer dan Mouse dengan ukuran 130 x 60 x $70 \mathrm{~cm}$.

\subsection{Analisis Ergonomi dan Antropome-} tri

Analisis ergonomi dilakukan untuk meminimalkan resiko kesehatan dan keselamatan dan kenyamanan dalam produk yang dirancang. Dengan begitu efisiensi kesehatan, keselamatan, dan kenyamanan dalam melakukan kegiatan menggunakan produk dapat maksimal. Sedangkan analisis antropometri dilakukan untuk mendapatkan dimensi atau ukuran produk yang sesuai dengan tubuh pengguna.

Ergonomi sangat diperlukan untuk membuat produk. Begitu juga dengan produk Meja Kerja ini. Ergonomi berarti aturan yang berkaitan dengan kegiatan bekerja dan meletakan dukumen pada tempatnya. Sasaran penelitian ergonomi adalah manu- sia pada saat bekerja lingkungannya, secara singkat dapat dikatakan bahwa ergonomi ialah penyesuaian tugas pekerjaan dengan kondisi tubuh manusia dengan tujuan kebutuhan sehari-hari yang akan dihadapi, yaitu dengan cara menyesuaikan ukuran area tempat Meja Kerja dengan dimensi tubuh agar tidak melelahkan.

Analisis ergonomi dilakukan untuk memin imalkan resiko kesehatan dan keselamatan. Dan juga agar kenyamanan dalam melakukan kegiatan menggunakan produk dapat maksimal, ergonomi sangat diperlukan untuk membuat produk. Aktifitas yang telah dianalisis membutuhkan fasilitas-fasilitas yang dapat digunakan pada saat melakukan aktifitas atau kegiatan pada saat mengambil dan meletakkan dokumen.

\section{Menentukan Lebar Meja Kerja}

Antropometri yang digunakan untuk menentukan jangkauan tangan ke depan menggunakan dimensi antropometri jarak genggaman tangan pada posisi tangan ke depan. Gender yang digunakan adalah wanita. Persentil $5 \%$, data yang didapat yaitu $630 \mathrm{~mm}$, untuk ukuran lebar meja yang akan digunakan adalah adalah $600 \mathrm{~mm}$. Ukuran tersebut dipilih agar pada saat pengguna ingin mengambil barang atau meletakkan barang pada sisi pojok meja dapat tersanggupi.

\section{Menentukan panjang meja kerja}

Antropometri yang digunakan untuk menentukan panjang meja kerja menggunakan dimensi antropometri jarak bentang dari ujung jari tangan kiri ke kanan. Gender yang digunakan adalah wanita. Persentil 5\%, data yang didapat yaitu 1.480 $\mathrm{mm}$. Sehingga panjang lebar meja kerja yang akan di buat adalah $1.300 \mathrm{~mm}$ di karenakan menyesuaikan ukuran pada ruang Kerja Staf SMAN 7 Samarinda.

\section{Tinggi Keseluruhan Meja Kerja}

Antropometri yang digunakan untuk menentukan tinggi keseluruhan meja 
kerja menggunakan dimensi tinggi siku pada posisi duduk, Gender yang digunakan adalah wanita. Persentil 5\%, data yang didapat yaitu $930 \mathrm{~mm}$. Ukuran tinggi meja yang akan digunakan adalah adalah $700 \mathrm{~mm}$ karena pemilihan tinggi ukuran meja disesuaikan dengan tinggi si pengguna sehingga membuat rasa nyaman dan pas pada saat digunakan dan menyesuaikan ukuran minimal tinggi meja kerja pada umumnya.

\section{Tinggi Meja Dari bawah sampai alas meja/kelonggaran meja}

Antropometri yang digunakan untuk menentukan Tinggi Meja Dari bawah sampai atap meja menggunakan dimensi tebal paha dan tinggi lipat lutut, Gender yang digunakan adalah wanita. Persentil $5 \%$, data yang di dapat yaitu $470,5 \mathrm{~mm}$., untuk ukuran tinggi meja dari bawah sampai atap meja yang akan digunakan adalah 470 dikarenakan menyesuakan dengan ukuran tinggi lipat lutut agar lebih nyaman pada saat bekerja. Dengan ditambah ukuran toleransi $5 \mathrm{~mm}$ sehingga ukuran kelonggaran meja menjadi $470,5 \mathrm{~mm}$.

\subsection{Analisis Konfigurasi}

Analisis konfigurasi yang dilakukan untuk mendapatkan susunan atau konfigurasi dari tiap - tiap komponen yang terdapat pada Meja Kerja ini. Berikut adalah gambaran dari konfigurasi produk berserta isinya hasil dari analisis yang telah dilakukan:
Peletakan sebelah kiri memiliki tiga buah rak tertutup dan satu buah rak terbuka yang mana sebagai tempat penyimpanan berkas - berkas pekerjaan yang sesuai dengan kebutuhan serta dapat menampung berkas pekerjaan. Sedangkan rak terbuka pada sisi kiri berfungsi sebagai tempat meletakkan kertas - kertas pekerjaan seperti absen siswa.

Pada bagian tengah memiliki sebuah laci yang mana dalam pekerjaan administrasi selalu menggunakan keyboard sebagai peralatan pekerjaan, sehingga dibuatlah laci keyboard yang sesuai dengan ukuran keyboard yang ada.

Pada bagian kanan meja terdapat satu buah rak terbuka dan satu buah rak CPU yang mana pada arak terbuka tersebut memiliki ukuran yang lebih besar dibanding rak terbuka pada sebelah kiri, karena sebagai tempat meletakkan peralatan kerja atau ATK. Sedangkan rak CPU wajib ada bagi para pengguna meja kerja karena sebagai peralatan penting dalam bekerja, sehingga dibuatlah rak CPU yang sudah di ukur sesuai ukuran yang ada.

Untuk rak terbuka sebagai tempat menyimpan kertas dan ATK diletakkan pada bagian atas dikarena agar lebih mudah pada saat meletakkan dan mengambil. Sedangkan untuk rak CPU diletakkan pada bagian kanan di karenakan pada umumnya peletakan CPU berada disebelah kanan sejajar dengan peletakan Printer.

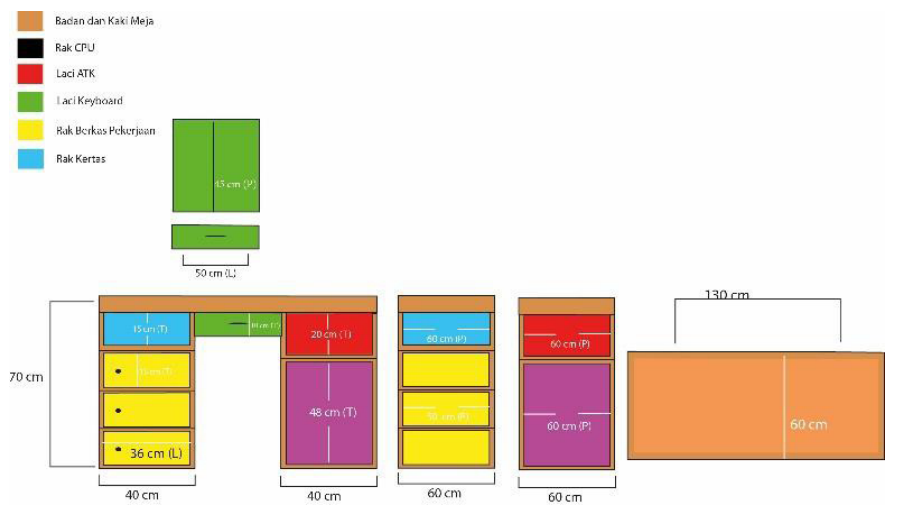

Gambar 1. Konfigurasi meja Sumber : Pribadi, 2019 
Vol. 6, No. 2, April 2019

\subsection{Analisis Sistem}

Analisis sitem perlu dilakukan untuk mengetahui sistem apa saja yang akan di gunakan dalam mendesain meja kerja staff administrasi SMAN 7 Samarinda.

\section{Sifat Konstruksi.}

Sifat konstruksi yang dapat diaplikasikan pada produk antara lain; permanen / fixed construction, lepas pasang / knocked down system. Dari analisis sifat konstruksi yang dilakukan, dipilihlah sifat konstruksi fixed construction karena memiliki tingkat kekuatan yang tinggi.

\section{Sistem Konstruksi.}

Sistem konstruksi dapat diaplikasikan pada produk adalah kontruksi permanen. Dalam permanen terdapat beberapa sistem kontruksi yang ada antara lain; konstruksi konvensional dan konstruksi kontemporer. Dari hasil analisis terpilih sistem konstruksi konvensional, karena konstruksi utama akan dibuat secara permanen dan tidak dapat dibongkar pasang sehingga kekuatan dari produk lebih terjaga.

\section{Sistem Sambungan Kayu}

Sistem sambungan kayu yang dapat diaplikasikan pada produk antara lain butt joints, dovetails joints, finger joints, mortise dan tenon joints. Dari hasil analisis terpilih sistem sistem sambung butt joints yang akan di gunakan. Dengan menggunakan sekrup sebagai pengunci dari sistem sambungan yang menyambungkan sisi potongan. Sekrup dipilih karena mudah didapatkan dan diaplikasikan. Sekrup juga memiliki kekuatan yang lebih baik dibandingkan dengan menggunakan paku.

\section{Sistem Sambungan Lekat}

Sistem sambungan lekat yang dapat di aplikasikan pada antara lain lem kuning, dan lem alifatik. Dari hasil analisis terpilih sistem sambung lekat yang digunakan menggunakan lem kuning sebagai perekat pada bagian alas meja kerja. Lem kuning ini memiliki kekuatan dan ketahan yang lebih baik dibandingkan dengan menggunakan lem alifatik.

\section{Sistem Geser Hardwares}

Sistem geser hardwares yang dapat di aplikasikan pada produk adalah rel kayu dan rel mekanik. Dari hasil analisis dipilihlah rel mekanik untuk melengkapi sistem geser pada produk meja kerja staf ini karena rel mekanik tidak gampang rusak, harga cukup terjangkau dan memiliki kekuatan serta mudah dalam proses pemasangannya dan juga lebih mudah didapat.

\section{Sistem Handle (Gagang)}

Sistem ini digunakan sebagai alat untuk memudahkan saat menarik laci. Terdapat beberapa sistem handle yang dapat digunakan untuk memudahkan saat menarik laci. Dari hasil analisis dipilih handle bronte untuk melengkapi laci atau loker pada produk meja kerja staf ini karena handle bronte sangat pas ditangan, dan mudah didapat.

\section{Sistem Penyangga}

Sistem penyangga yang diaplikasikan pada produk adalah pipa besi dan besi hollow. Dari hasil analisis di pilihlah pipa besi untuk melengkapi sistem penyangga pada produk meja kerja staf ini karena pipa besi tidak gampang rusak dan memiliki kekuatan yang sangat baik serta mudah dalam proses pemasangannya. Dan sesuai dengan konsep yang akan di aplikasikan pada meja kerja tersebut.

\section{Sistem Bantalan Kaki Meja}

Dari hasil analisis dipilihlah bantalan plastik untuk melengkapi sistem bantalan kaki meja pada produk meja kerja staf ini karena bantalan plastik selain harganya lebih murah, bantalan plastik juga lebih mudah di didapat dan proses pemasangannya pula tidak banyak memakan banyak waktu. 
M. Wakhid Bryan Adam, Darius Shyafary, Desain Meja Kerja Staf Administrasi

SMAN 7 Samarinda

\subsection{Analisis Material}

\section{Material utama}

Dari hasil analisis material yang dilakukan, dipilihlah multipleks sebagai material utama yang akan digunakan dalam pembuatan meja kerja terutama pada setiap bagian dari komponen-komponen yang ada pada meja sehingga meja dapat terkonstruksi dengan baik dan kuat. Multipleks sendiri memiliki keunggulan yang berbeda dari material kayu olahan lainnya seperti particle board, blockboard, multipleks dan MDF. Secara kualitas, yakni dari ketahanan dan kekuatan, kayu multipleks mampu mengimbangi kayu asli, sedangkan dari segi harga kayu multipleks jauh lebih terjangkau dibandingkan dengan kayu asli. Selain itu juga multipleks lebih mudah didapat di Samarinda. Secara estetik, kayu multipleks juga masih menampilkan pesona kayu yang sama dengan kayu asli karena memang terbuat dari lapisan kayu asli.

\section{Material Finishing}

Dari analisis yang telah dilakukan, dipilihlah material finishing HPL sebagai material finishing utama dari pada material finishing lainnya seperti cat duco, tacosheet dan melamic. Karena HPL sendiri memiliki ketebalan yang lebih disbanding tacosheet. Selain itu HPL juga memiliki kelebihan dari segi keberagaman warna corak dan memiliki kesan metalik. Dan kelebihan lainnya yang terdapat pada HPL adalah HPL memiliki kelebihan anti gores dan anti air. Tidak seratus persen anti gores, namun memang material ini kuat berkat bahan utamanya yang merupakan plastik keras PVC dengan permukaan bertekstur. Untuk dari segi perbandingan antara HPL, cat duco, dan melamic adalah dari segi biaya dan waktu pengerjaan atau pengaplikasiannya, HPL lebih praktis, lebih cepat dan lebih murah, oleh karena itu dampak yang ditimbulkan adalah berkurangnya omset.

\subsection{Analisis Bentuk}

Produk meja kerja yang akan diaplikasikan pada ruang kerja Administrasi SMAN 7 Samarinda yang memiliki ruangan tidak terlalu luas, sehingga diperlukan desain yang tidak terlalu besar. Dari sisi dimensi produk, gaya desain minimalis modern adalah gaya desain yang memungkinkan produk dibuat seminim mungkin dibandingkan gaya desain Bauhaus dan de stijl. Dari sisi produksi gaya desain minimalis modern lebih cepat dibandingkan gaya desain Bauhaus karena bentuknya yang dibuat sesimpel mungkin sehingga waktu produksinya tidak akan memakan banyak waktu.

\subsection{Analisis Warna \\ Warna Dominan}

Berdasarkan hasil survei di Ace Hardware terhadap furnitur meja kerja di dapatkan motif serat kayu paling banyak muncul, maka warna serat kayu alami akan di pakai sebagai warna dominan. Pilihan HPL motif dengan tekstur kayu asli keindahan dari tekstur, corak dan tampilan kayu memberikan keharmonisan antara perpaduan almiah dan modern nuansa dan natural pilihan warna kayu, lengkap dengan guratan-guratan lainnya. Kesan yang terbangun HPL bercorak kayu unik. Kehadirannya akan membuat furnitur minimalis akan lebih terkesan artistik. Warna kayu yang digunakan adalah warna kayu gelap/tua supaya dapat menimbulkan kesan formal dan profesional sesuai dengan peruntukannya sebagai meja kerja.

\section{Warna Aksen}

Berdasarkan hasil survei di Ace Hardware terhadap furnitur meja kerja di dapatkan warna hitam, putih dan krem paling banyak muncul dan akan di pakai sebagai warna aksen. Warna aksen yang diinginkan haruslah sesuai dengan konsep yaitu modern minimalist dan banyak digunakan oleh umum (sesuai trend), dan cukup kontras terhadap warna motif kayu yang merupakan warna dominan pada produk ini 
Vol. 6, No. 2, April 2019

(motif kayu wrna gelap/tua). Dari analisis diatas warna yang akan digunakan adalah dan HPL putih sebagai warna aksen.

\subsection{Proses Desain}

Langkah awal dalam mendesain produk adalah membuat sketsa awal. Sketsa - sketsa awal ini kemudian dianalisis dan dipilih sesuai kesesuian dengan spoesifikasi desain yang telah ditentukan. Dari beberapa sketsa awal terpilih sketsa seperti yang ditunjukkan dalam gambar 2 .

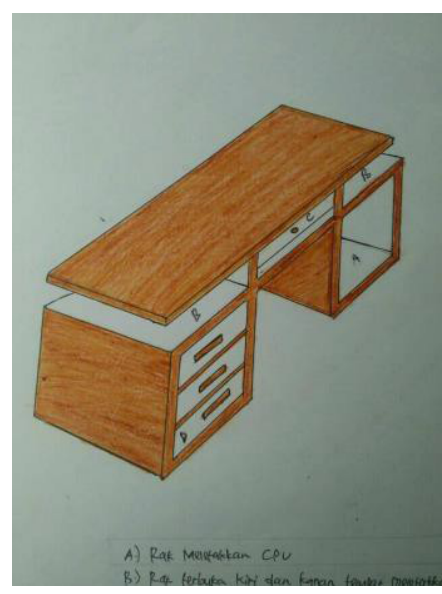

Gambar 2. Sketsa awal Sumber : Pribadi

Pada gambar alternatif di atas memiliki kelebihan yang sesuai dengan kebutuhan para pekerja sebagai staf administrasi, yang mana memiliki 3 buah laci tertutup sebagai tempat penyimpanan berkas pekerjaan, di tambah 2 laci terbuka yang dapat berfungsi sebagai tempat meletakkan barang elektronik berukuran kecil seperti handphone, buku, kertas printer maupun barang berukuran kecil yang lainnya. Serta memiliki rak terbuka berukuran besar sebagai tempat meletakkan CPU dan 1 buah laci keyboard.

Sketsa awal yang terpilih tersebut selanjutnya dikembangkan lagi menjadi beberapa alternatif pengemabngan desain. Selanjutnya alternatif-alternatif pengembangan desain tersebut dianalisis sesuai dehtgan spesifikas desain yang btelah ddi- tentukan. Dari hasil analisis terpilih desain alternatif pengembangan sepsrti yang ditunjukkan dalam gambar 3 .

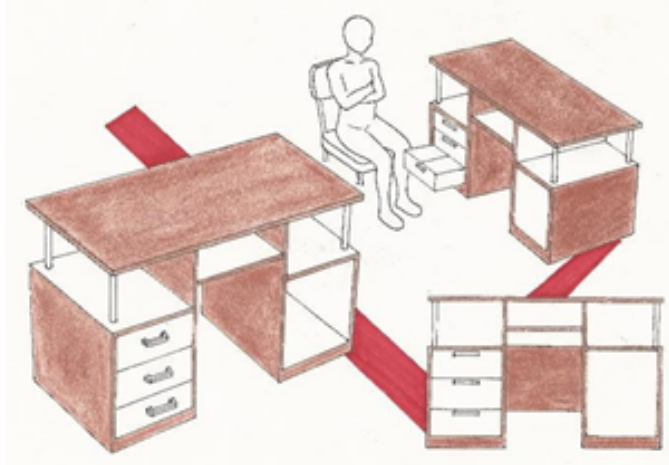

Gambar 3. Pengembangan desain Sumber : Pribadi

Pada gambar pengembangan di atas terlihat menggunakan beberapa sistem yaitu mulai dari handle jenis bronte sebagai penarik laci berkas, 4 buah pipa besi sebagai penyanggah alas meja agar pada saat di gunakan lebih kuat, dan di tambah bantalan alas kaki meja jenis paku rotan agar tidak melukai atau merusak keramik pada saat meja bergeser atau di pindahkan.

Desain terpilih tersebut selanjutnya dibuat simulasi model agar kelihatan sisi 3 dimensinya yang membantu mengapresiasi bentuk produk. Hasil simulasi model ditunjukkan oleh gambar 4. Dan hasil akhir dari desain ini adalah pembuatan purwarupa produk yang operasional sehingga bisa digunakan oleh konsumen seperti yang ditunjukijkan oleh gambar 5 . 


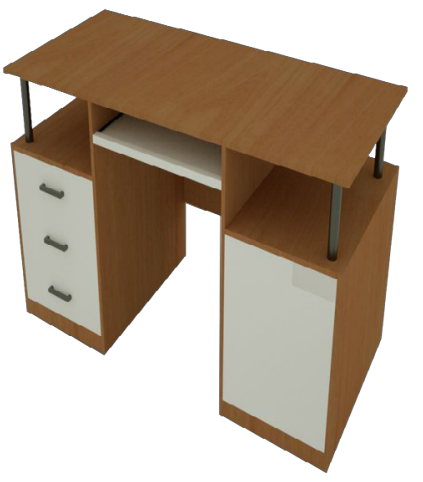

Gambar 4. Simulasi Modeling

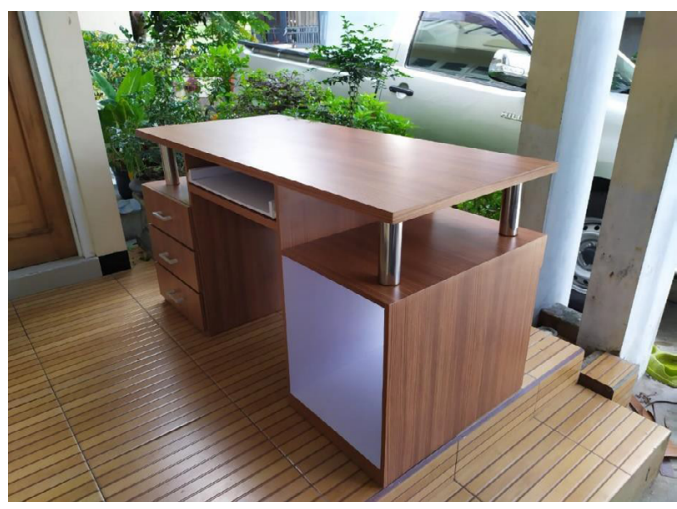

Gambar 5. Prototype Sumber: Pribadi

\section{Kesimpulan}

Kesimpulan dari hasil perancangan "Desain Meja Kerja Staf Administrasi SMAN 7 Samarinda" ialah sebagai berikut:

Meja kerja ini diperuntukkan kepada pengguan gander perempuan usia $25-$ 56 tahun. Meja ini memiliki dimensi ukuran panjang $130 \mathrm{~cm}$, lebar $60 \mathrm{~cm}$ dan tingi 75 $\mathrm{cm}$. Meja ini memiliki empat buah komponen diantaranya ruang penyimpanan berkas pekerjaan, ruang terbuka untuk meletakkan kertas printer A4, ruang menempatkan CPU dan ruang meletakkan keyboard. Meja ini memiliki bentuk gaya desain modern minimalis dan untuk warna yang digunakan adalah warna serat kayu gelap sebagai warna dominan serta warna putih polos sebagai warna aksen dengan menggunakan material finishing HPL.

Saran yang dapat diberikan adalah agar meja ini dapat di kembangkan lagi menjadi lebih baik dari bagian bentuk yang bervariatif serta memiliki rasa kenyamanan.

Dalam proses perancangan ini, penulis memiliki kendala pada bagian penyetoran material dan proses pembuatan yang memakan waktu cukup lama. Dengan demikian maka untuk dikemudian hari apabila produk ini ingin di kembangkan lagi alangkah baiknya pada saat pembelian material dan pemberian data produk pada workshop lebih cepat agar pada saat proses pembuatan tidak memakan waktu yang lama. 
Vol. 6, No. 2, April 2019

\section{DAFTAR PUSTAKA}

Akmal, Imelda dkk. (2007). Seru Rumah Ide Jendela Cantik. Jakarta: PT.Gramedia. Pustaka Utama. (5 Januari 2018). https://books.google.co.id/

Allen, Edward. (2005). Dasar-Dasar Konstruksi Bangunan. Jakarta: Erlangga. (10 Februari 2019). https://books.google.co.id/

Cahyadi, Dwi. (2014). Aplikasi Mannequin Pro Untuk Desain Industri. Cetakan Pertama. Yogyakarta: Leutikaprio.

Kristianto. (1987). Sekrup dan Safe. Andri Desu. (31 Maret 2019). https://www.scribd. com/document/403763760/.

Marizar. (2005). Studi Struktur dan Konstruksi Pada Kerajinan Mebel Bambu Di Desa Belega Gianyar Bali. I Nyoman Adi Tiaga. (24 Mei 2017). https://www.researchgate.net/ publication/317088767.

Manetsch dan Park. (1979). Dikutip Dalam Eriyatno, (1999). "Ilmu Sistem: Meningkatkan Mutu dan Efektivitas Manajemen”. Jilid Satu. IPB Press, Bogor.

Marizar. (2005). Designing Furniture, 2005. E.Supriyatna (2005). http://portal.kopertis3. or.id/bitstream/123456789/2155/1/.

Nurmianto. (1991). Data Antropometri Buku Eko Nurmantio. Sumber data: Stevenson, 1989. https://repository.maranatha.edu/4178/2/9823137_Appendices.pdf.

Suparto. (1979). Jenis Jenis Struktuk dan Konstruksi. Budi Tedjo. (2017). https://docplayer.info/38928218-Struktur-dan-konstruksi.html.

Swasty. (2010). Penerapan Metode Palette Untuk Menentukan Warna Dominan. Erfian Junianto. (April 2018). https://www.researchgate.net/publication/326482595.

Tikno I. (2008). Mengenal Konstruksi Kayu Untuk Furniture dan Bangunan. Esensi. Jakarta.

Yusuf. (2012). Sambungan Lem Yusuf. (02 Januari 2012). https://www.scribd.com/ doc/76929163. 